ReBEn, 36: 255-259, 1983.

\title{
PRÁTICA ADMINISTRATIVA DE ENFERMAGEMi NA REDE DE SERVIÇOS DE SAÚDE
}

\author{
* Stella Ma. P. F. de Barros
}

** Maria Jenny Silva Araújo

ReBEn/04

BARROS, S.M.P.F. e colaboradora - Prática administrativa de enfermagem na rede de Serviços de Saúde. Rev. Bras. Enf.: RS, 36: 255-259, 1983.

\section{RESUMO}

$\mathrm{Na}$ tentativa de refletir sobre a prática administrativa do enfermeiro na rede de serviços de saúde, faz-se uma análise histórica da mesma, percebendo-se assim a configuração dos fatores que determinaram a situação atual. A partir da compreensão da divisão técnica de trabalho de enfermagem, da força de trabalho assalariado, da rede de serviços de saúde, e do sistema econômico existente, constata-se o espaço objetivo da prática administrativa do enfermeiro. $\mathrm{O}$ confronto entre custo $\mathrm{x}$ qualidade, lucro x eficiência, leva-nos a entender a administração participativa como uma dasteorias mais significativas na busca de maior eficiência e produtividade.

A prática da enfermagem tem sido constante tema de reflexão dos enfermeiros, principalmente quanto a seus aspectos assistenciais.

A prática administrativa porém, não tem sido bastante contemplada nessas análises. Quando isto ocorre, é sempre colocada em oposição ao exercício da prática assistencial, na medida em que se considera o tempo gasto em atividades administrativas como um afastamento do enfermeiro da assistência ao paciente. O conflito existente entre estas duas funções da enfermagem só poderá ser compreendido na medida em que tentarmos refletir historicamente como essas práticas evoluiram e que condicionantes estruturais permitiram o dimensionamento das mesmas na sociedade.

A nossa proposta é discutir a prática administrativa do enfermeiro considerando-a, não como um obstáculo à prática assistencial, mas como um instrumento que possibilita uma assistência de enfermagem integral e igualitária para o indivíduo e a sociedade.

Como afirma ROTENBERG (10), a prática administrativa do enferineiro é influenciada pelas necessidades e demandas da comunidade na qual ela opera, determinada pela estrutura social. $O$ exercício da administração de enfermagem não se processa num espaço abstrato, mas em instituições de saúde, inseridas numa sociedade, sujeita às forças sociais, reflexo das relações de trabalho existentes no processo produtivo. Portanto, esta prática está sujeita aos impulsos ou barreiras que tais forças determinam.

A administração pode ser conceituada como o processo pelo qual o enfermeiro, através de teorias e técnicas, planeja, organiza, dirige e controla as atividades de enfermagem com o próposito de oferecer uma adequada assistência de enfermagem ao indivíduo e à sociedade. Para que esse processo possa acontecer, é necessário a presença de dois insumos básicos, que são os Recursos Humanos e Recursos Materiais, pois o trabalho de enfermagem requer uma força de trabalho humana e instrumental, fazendo com que o enfermeiro administrador se responsabilize, em última análise, pelos aspectos essenciais, a fim de que o sistema entre em funcionamento.

\section{Recursos Humanos}

Considerando-se o primeiro insumo, ou seja, os recursos humanos, alguns comentários merecem ser feitos.

Primeiramente como trabalhadores da área da saúde, representamos, junto com o pessoal auxiliar, o maior contingente de mão de obra nessa área, e assim possuímos um grande potencial de pressão. Ao lado disto, como profissionais assalariados, os enfermeiros compõem uma parcela da força de trabalho, e não detendo os meios de produção, sua participação no nível decisório é limitada.

Historicamente sabemos que na Inglaterra a divisão técnica do trabalho em enfermagem sucedeu à divisão social, com o aparecimento de duas categorias diferenciadas: as "lady nurses" (classe

\footnotetext{
* Prof. Adjunto da Escola de Enfermagem da Bahia

** Prof. Assistente da Escola de Enfermagem da Bahia
} 
BARROS, S.M.P.F. e colaboradora - Prática administrativa de enfermagem na rede de Serviços de Saúde. Rev. Bras. Enf.: RS, 36: 255-259, 1983.

A, trabalho intelectual, pagavam seus estudos, domínio do saber, função de administrar e ensinar) e as "nurses" (classe C, trabalho manual, estudo gratuito, domínio do fazer, função de assistir). (2).

Com esta divisão ficou estabelecido uma relação de dominante $\mathrm{x}$ dominado, na medida que $\mathrm{o}$ saber tornou-se monopólio das "lady nurses".

A hierarquia destas categorias, como também afirma OLIVEIRA (8), reproduz nd interior da relação de trabalho a estrutura de classe social, estando sempre no vértice da pirâmide os que controlam ou detêm o poder e na base aqueles que executam, mantendo de uma certa forma o "status quo", necessário à reprodução dos sistemas.

$\mathrm{O}$ aparecimento dos vários elementos auxiliares em épocas posteriores veio apenas aumentar a divisão técnica do trabalho já existindo. Porém com o ensino formal de algumas categorias e sua legitimação, o saber, antes monopólio dos enfermeiros, é dividido em algum grau com estas categorias, determinando uma disputa de poder bem mais conflitante.

Verificamos atualmente um esforço de trabalho conjunto das diversas categorias de enfermagem, na tentativa de, explicitando e trabalhando os conflitos, tentarem reunir esforços em busca de um caminho conjunto. Tarefa que, diga-se de passagem, não é das mais fáceis.

Vale ressaltar que para exercer sua prática, o enfermeiro administrador também estabelece relações com outros recursos humanos (profissionais da saúde, empresários, representantes de empresas de material, equipamentos e laboratórios e mesmo representantes sindicais). É sabido que cada um deles especificamente é fonte geradora de conflitos, que se não trabalhados poderão dificultar sua prática. Talvez, o exercício deste relacionamento seja mais difícil, na medida em que nesta relação não se estabelece a dominação existente na equipe de enfermagem por parte do enfermeiro, e sim uma relação de igualdade, quando não de dominado. Observa-se então que o enfermeiro administrador passa a ser intermediário no jogo de forças dentro da área da saúde, papel este bastante conflitante.

\section{Recursos Materiais}

Considerando-se o outro insumo referido, ou seja, os recursos materiais, verificamos que tradicionalmente o enfermeiro assumiu a postura daquele responsável pelo ambiente (limpeza, conservação), pela existência adequada do arsenal de equipamentos, material e medicamentos necessários ao trabalho médico e da própria enfermagem, ou de outros serviços.

Considera-se que a enfermagem moderna assinalou ritmo mais rápido no Brasil a partir de 1940, quando respondendo às injunções econômico-sociais, os primeiros hospitais escolas foram criados. (1). Neste espaço, o desempenho do enfermeiro foi requerido como administrador e educador e considerado por alguns autores como elemento essencial e indispensável à eficiência e eficácia dessa organização. É interessante observar que em determinadas instituições, encontram-se enfermeiros ocupando o cargo de coordenador de recursos materiais, enquanto que na mesma instituição inexiste a coordenação do próprio setor de enfermagem.

Colocam-se assim duas vertentes: a primeira, do enfermeiro como gerenciador de recursos humanos, que hoje representam cerca de $70 \%$ da força do trabalho nas instituições de saúde e correspondem a $60 \%$ do orçamento dos hospitais, e a segunda, como controlador dos recursos materiais, impulsionados pelo aparato industrial.

Rede de serviço de saúde quem serve?

Como se coloca então o enfermeiro administrador neste quadro? O que significa sua prática, a

Ora, para discutir mesmo que superficialmente estas indagações, se faz necessário uma reflexão, mesmo que de passagem, sobre o sistema capitalista em que vivemos, marcado de contradições já sobejamente citadas. Conceituar portanto, o processo administrativo é tarefa relativamente fácil, porém, trazer o conceito para a prática, inserida em uma determinada sociedade, requer de fato, alguma reflexão.

O sistema de saúde, nas sociedades capitalistas, tenta atender a três finalidades:

- reprodução e manutenção da força de trabalho necessária à produção;

- controle de tensões sociais geradas ao nível das desigualdades estabelecidas pela estrutura de classes;

- capitalização de recursos realizada através das indústrias de equipamentos e farmacêutica e dos grupos empresariais; 
BARROS, S.M.P.F. e colaboradora - Prática administrativa de enfermagem na rede de Serviços de Saúde. Rev. Bras. Enf.: RS, 36: 255-259, 1983.

Com o objetivo de se auto-reproduzir como sistema as duas primeiras são explicitadas, mesmo em documentos oficiais, o que não ocorre com a terceira, por razões óbvias.

Vários autores $(4,5,11)$ têm, através de estudos, demonstrado a presença destas três finalidades, além de que, também podemos presenciar, a existência das mesmas na medida em que procurarmos aclarar, no dia a dia, os porquês da existência de um programa ou ação na área de saúde.

Estes três objetivos obedecem a lógica do sistema capitalista que se reflete dentro do setor saúde e onde não esqueçamos nossa prática é exercida. A não observação destes gera incompreensões das situações, análises distorcidas, que camuflando a realidade dos fatos, colaboram na manutenção da situação.

A constante busca do papel do enfermeiro, a tão proclamada ausência de definição de funções, a não participação nas decisões a nível central, etc..., não podem ser analisadas como fenômenos isolados, mas sim dentro de um espaço histórico e social.

Sabemos que este espaço se encontra cheio de obstáculos e limitações para que seja alcançado o verdadeiro objetivo da prática administrativa do enfermeiro, na medida em que as necessidades de saúde da população não são sequer consideradas.

O campo de prática da enfermagem se encontra no setor público e privado da rede de serviços de saúde. As variáveis que intervém na configuração desta prática são múltiplas e complexas e nossa análise pode ser considerada simples reducionismo, porém, permitam-nos assim fazê-lo, numa tentativa de clarear a questão.

O Ministério de Saúde, as Secretarias de Saúde e em parte o Ministério da Previdência e Assistência Social são locais onde a prática administrativa se processa, visando prioritariamente o atendimento das duas primeiras finalidades (reprodução e manutenção da mão-de-obra e controle das tensões sociais) enquanto que a terceira é mais aparente no setor privado (grupos empresariais médicos) e no M.P.A.S. considerando que com sua política privatizante, torna-se simples repassador de recursos para o setor privado.

Compreender a lógica das instituições em que trabalhamos é de fundamental importância para que não nos tornemos meros robôs administrativos e passemos a ser enfermeiros conscientes do nosso compromisso com a assistência de enfermagem à população, percebendo que selecionar, treinar, supervisionar e avaliar pessoal, como também, solicitar, manter e controlar material só tem como objetivo a provisão de uma assistência de enfermagem adequada e igualitária.

Recentemente vários autores têm chamado a atenção para o excesso de importância dada à prática do enfermeiro especialista, que sem perceber, passam a consumir equipamentos e produtos farmacêuticos, nem sempre necessários à assistência do paciente (9). Também observa-se por outro lado, a ênfase recente na formação do enfermeiro generalista, que tem levado as escolas a se esquecerem da importância da prática administrativa, fazendo com que os enfermeiros saiam das escolas incapacitados de ocuparem cargos administrativos. Isto representa uma verdadeira contradição, pois cada vez mais está sendo requerido a presença deste elemento, como aquele responsável em última análise pelo controle de custo dos serviços de saúde, considerando a atual crise do sistema de saúde. Cabe porém ressaltar, que a sua necessidade não significa melhoria da assistência de enfermagem, mas como gerenciadora e controladora dos gastos.

TREVIZAN (12) ao estudar as atividades desempenhadas pelo enfermeiro em São Paulo, observa a tendência crescente da prática administrativa, sem porém se deter na análise dos porquês.

ALWARD (3) nos E.E.U.U. afirma que, existe uma certa pressão para que o enfermeiro seja de fato o responsável pela diminuição dos custos operacionais ao controlar recursos materiais e humanos.

Parece assim que o principal conflito não se encontra no fato de, o enfermeiro ao administrar não ter tempo para exercer a função de assistir, mas sim que a prática administrativa de enfermagem no atual sistema, impede uma assistência adequada. Constata-se assim um descompasso entre custo e qualidade, lucro e eficiência.

Poderíamos pensar que as teorias administrativas se bem aplicadas evitariam este problema. Percebe-se porém que as chamadas teorias clássicas ou algumas contemporâneas, não têm determinado modificações e nem mesmo satisfação no trabalho. Recentemente surgiu a chamada administração participativa, que, através da democratização das decisões, estabelece melhor satisfação no trabalho e aumento da produtividade (6).

$\mathrm{O}$ conhecimento da legislação trabalhista, padrões profissionais, direitos do consumidor e compreensão da crise econômica atual, além do saber específico em administração, são requisitos elementares para este tipo de administração, pois ela requer equalização de poder, descentralização de autoridade e participação nas decisões. Esta teoria tenta diminuir o espaço entre qualidade e custo de atendimento, visando maior produtividade e eficiência (7). 
BARROS, S.M.P.F. e colaboradora - Prática administrativa de enfermagem na rede de Serviços de Saúde. Rev. Bras. Enf.: RS, 36: 255-259, 1983.

A administração participativa tem sido experimentada apenas com os trabalhadores de saúde, porém, pode e deve ser ampliada para a clientela, seu principal objetivo, participe também.

\section{CONCLUSÕES}

Finalmente, gostaríamos de ressaltar que a prática administrativa do enfermeiro só se dará eficientemente, na medida em que:

1 - haja uma compreensão do contexto social em que se vive, dos reflexos desta nos serviços de saúde e da inserção da prática administrativa da enfermagem nesta realidade;

2 - sejam explicitadas e trabalhados os conflitos existentes entre os recursos humanos (pessoal de enfermagem e outros profissionais da saúde), visando o mesmo objetivo: a assistência de saúde integral, contínua e igual à comunidade;

3 - os recursos materiais (equipamentos, medicamentos) sejam visualizados não como um fim em si mesmos, mas como um insumo necessário à produção do atendimento;

4 - a capacitação do enfermeiro na área administrativa seja enfatizada nos cursos de graduação e pós-graduação, com a utilização de teorias capazes de favorecer práticas democráticas;

5 - sejam acionadas as estratégias de descentralização e hierarquização das ações de saúde, que viabilizando um Sistema Único de Saúde, venham a facilitar um processo administrativo que atenda de forma igualitária à população;

6 - o processo de democratização da sociedade permita a participação da população nos processos de decisão nos diferentes níveis administrativos.

Acreditamos que outros pontos devam ser acrescentados, na medida em que de fato uma administração participativa estabeleça o diálogo e discussão entre os enfermeiros o pessoal de enfermagem e a clientela.

\section{SUMMARY}

In an attempt to think over the administrative practice of nurses in the network of health services we undertake a historical analysis of it and discover the pattern of factors that came to determine the present situation. By considering the technical division of the nursing work, the salaried work force, the network of health services and the prevailing economic system we find out objetive space for the administrative practice of nurses. The questions of cost versus quality and of profit versus efficiency make us perceive participative management as one of most meaningful theories in the search of greater efficiency and productivity.

\section{BIBLIOGRAFIA}

1. ALCÂNTARA, G. de - A enfermagem moderna como categoria profissional: obstáculos à sua expansão na sociedade brasileira. Ribeirão Preto, 1966. Tese (cátedra) - Faculdade de Medicina de Ribeirão Preto, USP.

2. ALMEIDA, M. C. P. et alii - Contribuição ao estudo da prática de enfermagem - Brasil, p. 61 . mimeog.

3. ALWARD, R.R. Nursing Administration in Crises Nurs-Forum, 19 (3): 242-53, 1980.

4. DONNANGELO, M. C. \& PEREIRA, L. Saúde e Sociedade, 1a ed. São Paulo Duas Cidades, $1976,124 \mathrm{p}$.

5. LUZ, M. T. As instituiçōes Médicas no Brasil; instituição e estratégia de hegemonia. 2a ed. Rio de Janeiro, Graal, 1979. 295 p.

6. MARITZ, D.G. Monagement Principles and Nursing: The inefficiency of efficiency Superv. Nur., 40-41, march 1980.

7. MOHNEY, S.J. Why participative monagement in the modern hospital? Super. Nurs. 36-37, may 1980.

8. OLIVEIRA, M.I.R. Saúde para todos e a inserção da enfermagem nas instituições de saúde. R. Paul. Enf., 1 (1): 23-27, jul/ago 1981.

9. PAIM, L. et alii. As inovações no ensino superior de enfermagem face a assistência à saúde da população Possibilidades e limitações. In: CONGRESSO BRASILEIRO DE ENFERMAGEM, 30., Belém 16 de 22 de julho 1978. Anais... Brasília, ABEn, 1978. p. 111-5.

10. ROTENBERG, A Nursing a Social Service - consideration for nursing administration Inter. Nur. Rev. 27 15): 146-147, sept/out 1980. 
BARROS, S.M.P.F. e colaboradora - Prática administrativa de enfermagem na rede de Serviços de Saúde. Rev. Bras. Enf.: RS, 36: 255-259, 1983.

11. SINGER, P et alii - Prevenir e Curar o controle social através dos Serviços de Saúde. Rio de Janeiro, Forense-Universitária, 1978.

12. TREVIZAN, M. A. et alii - Atividades administrativas desempenhadas por enfermeiros - chefes Rev. Paul. Hosp. 23 (7): 204-210, jul. 1980.

UTILIZAÇÃO DO “SORO CASEIRO” NAS DOENÇAS DIARRÉICAS:
UM PROGRAMA DE PROMOTORES DE SAUUDE DO BAIXO AMAZONAS.

* De Anne Karen Hilfinger Messias

ReBEn/05

MESSIAS, A.K.H. - Utilização do "Soro Caseiro" nas doenças diarréicas: um programa de promotores de Saúde do Baixo Amazonas. Rev. Bras. Enf.: RS, 36: 259-265, 1983.

\section{RESUMO}

Reidratação oral, iniciado do princípio da diarréia. pode combater efetivamente a desidratação, eliminar uma dependência de recursos e tecnologia de tratamento parenteral e prevenir uma resultante desnutrição. $\mathrm{O}$ êxito desta terapia é um avanço importante na rea de doenças diarréicas. $\mathrm{A}$ sua base científica se encontra na fisiologia da absorção de água e eletrólitos pela mucosa do intestino delgado. Num programa de assistência primária, é necessário criar uma tecnologia apropriada que facilite a transferência dos conhecimentos científicos à realidade das condições locais. A autora atua na zona rural do Baixo Amazonas, uma região onde a diarréia figura entre as causas principais de morbidade e mortalidade infantil. Este trabalho descreve os métodos utilizados para a divulgação e implementação do "Soro Caseiro" através de elementos comunitários treinados para serem Promotores de Saúde.

\section{INTRODUÇÃO:}

"O fenômeno fisiopatológico mais importante na enterite aguda é a espoliação hidreletrolítica que sofre o organismo, conseqüente à secreção exagerada de eletrólitos e água pela mucosa do intestino delgado. Essa perda ocorre, em maior ou menor grau, em todos os casos, sejam eles provocados por bactérias enterotoxigênicas, bactérias invasivas ou vírus". (Pernetta, p. 37).

Assim sendo, a desidratação domina o prognóstico e o tratamento da enterite aguda. Na área de doenças diarréicas, uma das descobertas mais importantes em tempos recentes é que a desidratação nos casos de diarréia aguda, de qualquer etiologia, em qualquer faixa etária, pode ser tratada com êxito através de uma terapia de reidratação oral, utilizando uma única solução. Esta solução é preparada pela adição de glicose, cloreto de sódio, bicabornato de sódio e cloreto de potássio à água potável. Proporcionando concentrações apropriadamente adaptadas para facilitar a absorção intestinal de água e eletrólitos, a finalidade da solução de reidratação oral é justamente repor a perda destas mesmas substâncias devida à diarréia aguda. Administrada oralmente, esta solução é absorvida no intestino delgado, ainda que haja diarréia copiosa. Várias pesquisas em adultos, crianças e recém-nascidos têm contribuído para estabelecer a segurança e eficácia desta arma simples e importante da saúde pública.

É de primeira necessidade começar o tratamento reidratante logo no início da diarréia. A eliminação de água pelas fezes é o fator principal na origem da desidratação. Mas também ocorrem vômitos. A febre (comum na enterite aguda) e a acidose (resultante da acentuada perda de líquidos e eletrólitos) aceleram a respiração e suor, agravando ainda mais a situação. O perigo de desidratação é ainda

(*) Enfermeira de Saúde Pública, Coordenadora de Saúde Comunitária da Fundação Esperança, Santarém - Pará - Brasil. 